\title{
Tobacco sales to minors in 97 US and Canadian communities
}

\author{
Thomas E Radecki, C Dianne Zdunich
}

\begin{abstract}
Objective - To establish a US and Canadian baseline of the willingness of merchants to sell tobacco products to minors and to encourage improved compliance with laws prohibiting the sale of tobacco to minors.

Design - A sampling of 2337 retail tobacco merchants in 93 US and four Canadian communities were tested with 15- and 16year-olds attempting to purchase cigarettes. Merchants in 11 US cities were retested 12 to 18 months later.

Intervention - City, state, provincial, and national governments were notified of the results.
\end{abstract}

Main outcome measures - Cigarette sales to minors.

Results - The minors were able to purchase cigarettes at $77 \%$ of US and $93 \%$ of Canadian stores in the cities sampled. Cities with tobacco ordinances $(n=11)$ did better (average purchase rate $=49 \%$ ) than those without (83\%). Cities in states with laws prohibiting the sale of tobacco to minors under 16 and 17 years old tended to do worse and those with a 19year-old limit tended to do better compared to those with an 18-year-old limit. Four city governments started or modified compliance check programmes because of the survey findings.

Conclusion-It appears that merchants in very few communities in the US or Canadian cities tested are adequately complying with laws prohibiting tobacco sales to minors. Low-cost tobacco purchase surveys were of some value in stimulating enforcement, but change requires additional municipal, state and/or federal legislation and systematic and effective enforcement efforts.

(Tobacco Control 1993; 2: 300-5)

\section{Introduction}

Tobacco usage is responsible for the deaths of

Doctors \& Lawyers for a Drug Free Youth, Urbana, Illinois, USA T E Radecki

C D Zdunich

Correspondence to: T E Radecki, Doctors \& Lawyers for a Drug-Free Lawyers for a Drug-Fre
Youth, $705 \mathrm{~W}$ Oregon. Urbana, IL 61801, USA a lack of respect for, and enforcement of, laws prohibiting the sale of tobacco to minors is the international norm, not the exception. In Santa Clara, California, $74 \%$ of stores sampled sold tobacco to minors. ${ }^{3}$ In Massachusetts, an 11year-old bought cigarettes from $75 \%$ of stores tried. ${ }^{4}$ In Buffalo, New York, despite educational efforts directed at the merchants, $77 \%$ of stores sold to minors, ${ }^{5}$ while in Tokyo $97 \%{ }^{6}$ and in London and Norway $78 \%$ and $90 \%$, respectively, ${ }^{7}$ sold cigarettes to minors. This is not just a recent phenomenon, as many of the laws in the US are over 100 years old with few reports of enforcement at any time in the past.

Studies, published and unpublished, of individual US cities since 1987 have reported that between $70 \%$ and $100 \%$ of merchants sell cigarettes to minors of varying ages. ${ }^{3-5,8,11}$ These studies, perhaps 20 in number, have used youths of varying ages, and different methodologies.

About half of American smokers become addicted to tobacco by the age of 18 years, before it is legal for them to purchase tobacco products. ${ }^{9}$ Those who start younger are more likely to be heavy smokers as adults, ${ }^{10}$ have a harder time stopping smoking, and suffer a considerably higher rate of lung cancer.

Three recent research projects have linked low-cost enforcement of tobacco age laws by police or health officials to dramatic decreases in the rates of underage smoking. A Woodridge, Illinois, study focused on 13- and 14year-olds smoking and used youths of this age in enforcement checks. ${ }^{11}$ The rates of smoking by youths of this age in the local junior high school decreased by $50 \%$ after two years of quarterly compliance checks of all tobacco merchants by police officials.

A similar study in Leominster, Massachusetts, with comprehensive compliance checks three times a year using 16- and 17year-old teenagers found, on average, a $38 \%$ decrease in smoking prevalence for age groups from 13 to 17 years old. ${ }^{12}$ A study in Everett, Washington, found a $22 \%$ decrease in underage smoking after less than one year of enforcement. The actual level of enforcement is not described, but was less intensive. ${ }^{13}$ The decreases in smoking in these three studies are among the highest ever reported in any type of teenage tobacco prevention intervention and among the least expensive.

In order to establish more uniform baseline North American measures and to encourage minors can purchase tobacco products in the US, Europe, and Asia have demonstrated that 35000 Canadians are estimated to die annually

from tobacco-induced illness.
Numerous studies of the ease with which 
more widespread enforcement of the tobacco age laws, a 97-community tobacco purchase research project was undertaken.

\section{Methods}

This study represents a sample of 93 US communities in 37 states and four major Canadian cities in the two most populous provinces. Cities were selected based upon larger populations, and those most easily surveyed by a travelling research team. The Illinois selection attempted to cover all major Illinois cities and a sample of smaller cities and towns. Cities in other states were selected to cover as many states as possible within budgetary limitations. The purchase attempts were made between August 1991 and March 1992 for the first US survey, in June 1992 for the Canadian survey, and in winter 1993 for the Illinois follow-up study. In all US cities, 16year-olds were used for uniformity. In Canada, 15-year-olds were used since Quebec had a 16year-old age limit at the time of the study, while Ontario had an 18-year-old limit.

The youths were under the supervision of adults and written permission was obtained for their participation from their parents. Youths were instructed to enter the store, request a specific brand of cigarettes, pay, and leave. They were told to say they were 18 years old if asked.

In each city between 20 and 50 stores were tested. Some small Illinois towns had fewer than 20 merchants tested. The stores tested included all over-the-counter tobacco merchants passed on streets while driving randomly throughout the city. Neighbourhoods considered physically dangerous were avoided. A small number of vending machines, primarily in motels and restaurants, were also tested.

Youths used in the study were nine Caucasians and two Hispanics, six male and five female. The youths travelled by car from central Illinois one or two at a time with one or two supervising adults. Each youth was used for six to 15 cities except the two Hispanics, who were used only in Los Angeles. The purchase research in the three San Francisco Bay area cities was done by the Youth Leadership Institute staff and additional 16year-old youths.

Youths looking markedly older or younger than 16 years old were not used in the study. An age-testing procedure of having supermarket patrons guess the ages of the youths was used to aid in this determination. Several were rejected because they appeared older than 16. All but one of the youths in the study were non-smokers.

Several cities were retested to measure change over time, or to confirm initial findings. Time of day of sampling of the various cities differed considerably although all purchase attempts were made outside of normal school hours.

Truly random selection of tobacco outlets was not possible for two reasons. An actual listing of tobacco outlets was available in very few communities due to a lack of tobacco retailer licensing. In addition, a true random selection would have been beyond the financial resources available for this study.

Cities with tobacco ordinances were those recently enacting specific legislation on tobacco sales to minors (10 cities) or announcing a specific programme of enforcement using existing health licenses (Providence, Rhode Island). Only two of the 11 cities that were placed in this category were actually doing any enforcement at the time of our initial surveys (Woodridge and Bolingbrook, Illinois). Information on enforcement practices was obtained by telephone contact with appropriate city officials, or local citizen groups.

\section{Results}

A total of 2337 purchase attempts were made as part of this study. The overall purchase rate in the US was $77 \%$ and in the four Canadian cities $93 \%$; in other words, $23 \%$ of US but only $7 \%$ of Canadian merchants refused to sell cigarettes to the youths involved in this study. The individual cities are listed in table 1.

Only relatively minor differences were found between purchase rates for the nine different youths used in more than one city each, although they were usually sampling different cities. Each youth had at least one city where $94 \%$ or more of merchants sold tobacco to that youth. The four cities with the lowest purchase rates were each coincidentally sampled by a different youth.

Little difference in refusal rates was noted between male and female youths used in this study. In the US part of the study, male youth purchased cigarettes $78 \%$ of the time, while female youth purchased $75 \%$ of the time.

Sixteen communities had a $100 \%$ purchase rate, while only four cities had purchase rates under $40 \%$. Nine of the cities tested had tobacco ordinances at the time of this initial survey although only two were doing any enforcement. Two later added ordinances and were retested. These 11 cities had an average purchase rate of $49 \%$ compared to $83 \%$ for the 88 cities without ordinances (two cities are in both categories). When analysed by the total number of purchase attempts, the proportion of refusals in cities with an ordinance was $51 \%(147 / 287)$, compared to $24 \%(440 / 1851)$ for cities without an ordinance $\left(\chi^{2}=92.6\right.$, $\mathrm{p}<0.001$ ).

In the US cities tested in states with a lower age limit, ie, 16- and 17-year-old age limits (Kentucky, Georgia, Delaware), had a much lower average refusal rate $(3 \%)$ than those in states with an 18-year-old age limit (23\%). The two cities tested in states with 19-year-old age limits (Utah and Alabama) had a much higher average refusal rate $(54 \%)$. When analysed by the total number of purchase attempts, the proportions of refusals were $3.2 \%(2 / 63), 25.7 \%(473 / 1842)$, and $65.8 \%$ $(27 / 41)$ for cities in states with a $16-$ or 17 year-old age limit, an 18-year-old limit, or a 19-year-old limit, respectively $\left(\chi^{2}\right.$ for linear trend $=47.4, p<0.001)$. The two Ontario 
Table 1 Tobacco purchase rates in 97 US and Canadian communities

\begin{tabular}{|c|c|c|c|}
\hline \multicolumn{4}{|c|}{ Tobacco purchase rates $(\%)$} \\
\hline Cities in the US & & New Orleans (20) & 87 \\
\hline Alabama: Mobile (25) & 64 & Maryland: Baltimore (20) & 90 \\
\hline Arkansas: & & Michigan: 5 Detroit suburbs (30) & 17 \\
\hline Little Rock (25) & 4 & Minnesota: Minneapolis (25) & $44^{\star}$ \\
\hline retest (15) & 13 & Mississippi : & \\
\hline Arizona: Tucson (30) & 83 & Gulfport (20) & 90 \\
\hline California: & & Pascagoula (20) & 100 \\
\hline Los Angeles (30) & 80 & Missouri: & \\
\hline Oakland $(30)$ & 90 & Kansas City (25) & 100 \\
\hline San Diego (30) & 87 & St. Louis $(76)$ & 86 \\
\hline San Francisco (30) & 88 & retest after ordinance (15) & 47 \\
\hline San Jose (30) & 92 & Nebraska: Omaha (25) & 64 \\
\hline Colorado: Denver (25) & 52 & Nevada: Las Vegas (25) & 100 \\
\hline Connecticut: New Haven (20) & 100 & New York: & \\
\hline Delaware: Wilmington (25) & 92 & Albany (20) & 100 \\
\hline District of Columbia (25) & 84 & Brooklyn (25) & 100 \\
\hline Florida: & & Manhattan (25) & 88 \\
\hline Jacksonville (20) & 70 & New Jersey: Trenton (25) & 72 \\
\hline Pensacola (20) & 60 & New Mexico: Albuquerque (25) & 72 \\
\hline Tallahassee $(20)$ & 53 & North Carolina: & \\
\hline Georgia: Savannah (20) & 100 & Durham (20) & 85 \\
\hline Illinois: & & Raleigh (20) & 80 \\
\hline Bloomington (1991) (25) & 92 & Ohio: & \\
\hline Bloomington (1993) (17) & 100 & Dayton (20) & 55 \\
\hline Bolingbrook (10) & $40^{\star}$ & Toledo (20) & $40^{\star}$ \\
\hline Champaign (1991) (25) & 92 & Oklahoma: Oklahoma City (25) & 92 \\
\hline Champaign (1993) (20) & 80 & Pennsylvania: & \\
\hline Charleston (16) & 94 & Philadelphia (25) & 100 \\
\hline Charleston (12) & 100 & retest $1992(20)$ & 100 \\
\hline Chicago (1991) (30) & $53^{\star}$ & Rhode Island: & \\
\hline Chicago (1992) (30) & $87^{\star}$ & Providence (25) & 92 \\
\hline Mattoon (1991) (19) & $79^{\star}$ & after ordinance (25) & $72 \star$ \\
\hline Mattoon (1993) (15) & 54 * & South Carolina: Columbia (25) & 80 \\
\hline Normal (1991) (10) & 90 & Tennessee: Memphis (35) & 66 \\
\hline Normal (1993) (13) & 100 & Texas: & \\
\hline Peoria (1991) (25) & 92 & El Paso (20) & 85 \\
\hline Peoria (1993) (28) & 92 & Dallas (25) & 80 \\
\hline Schaumburg (1992) (20) & $50^{\star}$ & Fort Worth (20) & 65 \\
\hline Schaumburg (1993) (52) & $52^{\star}$ & Houston (25) & 84 \\
\hline Springfield (1991) (37) & 86 & Virginia: & \\
\hline Springfield (1993) (22) & 86 & Alexandria (20) & 65 \\
\hline Urbana (1991) (18) & 94 & Richmond (20) & 85 \\
\hline Urbana (1993) (20) & 85 & Utah: Salt Lake City (25) & $28^{\star}$ \\
\hline Woodridge $(10)$ & $70^{\star}$ & Wisconsin: & \\
\hline 22 more towns \& cities & 85 & Madison (20) & 55 \\
\hline Indiana: & & Milwaukee (25) & 76 \\
\hline Ft. Wayne (20) & 54 & Wyoming: Cheyenne (25) & 68 \\
\hline Indianapolis (20) & $\begin{array}{c}0^{\star} \\
48\end{array}$ & Cities in Canada & \\
\hline $\begin{array}{l}\text { Iowa: Des Moines (25) } \\
\text { Kansas: Topeka }(25)\end{array}$ & $\begin{array}{l}48 \\
88\end{array}$ & $\begin{array}{l}\text { Cities in Canada } \\
\text { Quebec City }(20)\end{array}$ & 100 \\
\hline Kentucky: Paducah (20) & $\begin{array}{r}80 \\
100\end{array}$ & Toronto $(30)$ & 97 \\
\hline Louisiana: & & Montreal (20) & 95 \\
\hline Baton Rouge (20) & 100 & Ottawa $(20)$ & 85 \\
\hline
\end{tabular}

$\star$ Cities with tobacco ordinances.

Numbers in parentheses $=$ number of merchants tested.

Table 2 Cigarette sales to minors by type of retailer ${ }^{\star}$

\begin{tabular}{lcc}
\hline Type of retailer & $\begin{array}{c}\text { Sales to } \\
\text { minors (\%) }\end{array}$ & $\begin{array}{c}\text { Number of outlets } \\
\text { selling/number of } \\
\text { stores tested }\end{array}$ \\
\hline Restaurants/motels & 100 & $32 / 32$ \\
Convenience stores/delis & 83 & $237 / 285$ \\
Gas stations & 79 & $490 / 619$ \\
Groceries/supermarkets & 73 & $194 / 267$ \\
Liquor stores/bars & 68 & $66 / 97$ \\
Pharmacies & 68 & $28 / 42$ \\
\hline
\end{tabular}

* This analysis covers 1342 stores.

cities with an 18-year-old age limit had an average refusal rate of $9.0 \%$ vs $2.5 \%$ for the two cities in the province of Quebec which has a 16-year-old age limit.

Purchase rates differed according to the type of establishment tested, as shown in table 2.

Among cities sampled more than once, the findings were consistent. On separate occasions three months apart using two different youths, Little Rock, Arkansas, merchants were found to be very reluctant to sell tobacco products to the 16-year-olds (purchase rates of $4 \%$ and $13 \%$ ). In other cities tested twice, the three cities that had instituted specific measures to decrease sales to minors showed some improvement, while those without new ordinances or new enforcement of existing ordinances did not show overall improvement. Those without changes in tobacco ordinance status or enforcement and their first and second purchase rates were: Philadelphia, Pennsylvania, (100\% and $100 \%$ ), Chicago, Illinois (IL) $(54 \%$ and $87 \%$ ), Charleston, IL, (94\% and $100 \%)$, Bloomington, IL, (92\% and $100 \%$ ), Normal, IL, (90\% and $100 \%$ ), Champaign, IL, $(92 \%$ and $80 \%)$, Schaumburg, IL, (50\% and $52 \%$ ), Urbana, IL, (94\% and $85 \%$ ), Springfield, IL, $(86 \%$ and $86 \%$ ), Peoria, IL, (92\% and $82 \%$ ). Chicago and Schaumburg both had unenforced tobacco licensing ordinances.

The two cities starting compliance checks of a small number of merchants and with merchant fines for sales to these minors after the first survey showed small improvements: Providence, Rhode Island (92\% and $77 \%$ ), and Mattoon, IL, (79\% and 52\%). After the initial survey, St. Louis, Missouri, passed a tobacco ordinance without enforcement. Merchant compliance improved as would have been 
predicted by the average compliance rates of cities without and with tobacco ordinances ( $86 \%$ and $47 \%$ ).

Of the two small Illinois communities already doing regular enforcement checks, Woodridge had been using 13-year-olds and reporting a purchase rate of $4 \%$. We found a purchase rate of $70 \%$ when a 16 -year-old was used. The second community, Bolingbrook, had been doing quarterly checks of all merchants with 16- and 17-year-olds with a police purchase rate of $18 \%$ only to have this rate jump to $35 \%$ after a six-month lapse between police checks. In our survey it was $40 \%$.

In Little Rock, Arkansas, all 12 attempts to purchase at gas station vending machines were unsuccessful. Of seven Schaumburg vending machines with automatic locking devices to be activated by restaurant staff, and tested in the 1993 sample, five purchases were made as the machines had been left in an activated state. Of 52 other vending machine purchase attempts in the study, no more than three in any one city, 50 attempts were successful.

\section{Discussion}

The overall US purchase rate of $77 \%$ was very disappointing but consistent with previous studies of individual cities. ${ }^{3,4,8}$ Because of the small number of merchants tested in each city and lack of true random selection, the figures for individual cities should only be considered rough approximations of the true rates.

The decision to have the underage youths say that they were 18 years old was based on a small survey of 20 underage smokers in Decatur, Illinois, before the study. That survey found that $75 \%$ reported they lied when confronted about their ages while attempting to purchase cigarettes. Most of the rest had never been confronted. Although, because of a past court ruling on police compliance checks of alcohol age law enforcement, ${ }^{14}$ police do not allow minors under their supervision to misrepresent their ages in alcohol compliance checks, to have done so in this study would have underestimated the true rate at which merchants are willing to sell cigarettes to minors without requiring reasonable proof of age.

The percentage of merchants selling to minors after the minors misrepresented their ages in this study was only $10 \%$. This means that only a few merchants will accept the word of a person who appears 16 years old but states he is 18 years old.

At no time during or after the study were the youths threatened with arrest despite having been turned down over 500 times. In roughly half the states tested, it was illegal for youths to attempt to purchase cigarettes. Merchants were not aware that the youths involved were part of a research project. Even in cities such as Rockford, Illinois, and Des Moines, Iowa, where legislation had recently been enacted with considerable news media coverage to fine youths up to $\$ 500$ for purchasing cigarettes, we found high buy rates and no effort to arrest the youths in establishments where they were refused. This suggests that such laws result in no change in merchant behaviour. We also think that these large fines, higher than many communities impose on merchants who illegally sell tobacco products to minors, are excessive.

Although a 16-year-old was used in Kentucky where the minimum age for legal sales was 16 at the time of this study, no establishment asked the youth's age or requested to see proof of age. Since there is a wide variance in age appearance according to our own experience with age testing, a fair number of 14- and 15-year-olds will look the same age as the youth we used in the study. The $100 \%$ purchase rate in the Kentucky city is probably reflective of a serious problem with merchant sales to minors.

The results obtained in the eleven cities retested in our study suggest that a sizeable change in merchant behaviour is unlikely to occur in the absence of specific enforcement intervention. This is also similar to findings in other reports of single cities. ${ }^{5,15-17}$

The city mayor's office in each city and governor's office in each state had also been notified of the research findings after the first purchase study. Only the cities of Mattoon and Schaumburg, Illinois, and Providence, Rhode Island, are known to have begun specific programmes in response to this study. In each case compliance check programmes have been used. Schaumburg and Mattoon already had unenforced tobacco ordinances, while Providence used a variety of existing health and liquor licensing requirement to enforce the tobacco age law.

Of the cities studied, only Schaumburg has instituted a comprehensive compliance check programme of all merchants. The 1993 Schaumburg figures in this paper reflect the beginning of that programme. Woodridge, Illinois, the fourth city instituting changes because of the findings of this study, revised its testing procedure and started using 16- and 17-year-old youths instead of 13-year-olds after becoming aware that merchants were selling much more readily to older minors. Woodridge now reports a purchase rate by 16 and 17 -year-olds of under $30 \%$.

The relatively small response by city and state governments following this tobacco purchase research study is in contrast to a much better response found by two research projects on alcohol sales to minors. ${ }^{18-20}$ In these studies, many more of the cities surveyed made specific changes in enforcement procedures, often instituting episodic or comprehensive compliance check programmes.

This poor short-term response to the tobacco purchase findings by governmental bodies compared to response to the alcohol purchase research may be due in part to a lack of already established governmental agencies assigned responsibility for enforcing the law prohibiting the sales of tobacco products to minors. Even the passage of excellent new licensing laws did not lead to enforcement in eight out of ten cities in this study. 
The number of cities with age laws other than 18 in this study is small, but the trend is in the direction of better compliance with a higher age limit. This suggests that raising the tobacco age limit may help to decrease access to tobacco products among minors already under the existing legal age limit. This finding adds additional support to calls for a 19-yearold $^{21}$ or a 21-year-old tobacco age law.

The $100 \%$ purchase rate of sales in restaurants and motels was due to the fact that these were almost all vending machine purchases. Pharmacies and liquor stores had the lowest purchase rates $(68 \%)$.

Of interest is the possibility that enforcement of alcohol sales and of tobacco sales to minors may have an effect on each other. Besides the above-noted lower sales rate for liquor stores, three of the four cities that did well in our tobacco survey (Little Rock, Salt Lake City, and suburban Detroit) had active alcohol compliance check programmes, something still uncommon in the US. ${ }^{18,19}$

The higher sales rate in Canada with only $7 \%$ of merchants refusing to sell vs $23 \%$ in the US might be a chance finding, or may be due to specific factors. These may include the lack of any Canadian city tested having had a specific tobacco licensing ordinance, the lower 16-year-old tobacco age limit in Quebec, and the lower 18-year-old drinking age laws in Ontario and Quebec vs the 21-year-old drinking age law in the US. Although the US figures are quite poor, they appear somewhat better than those of other countries where similar studies have been conducted on tobacco sales to minors (references 6 and 7 and unpublished data for Brazil, Uruguay, and Argentina collected by the author).

The data from this study, when combined with other reports of tobacco purchase research, suggest that model licensing laws per se do not adequately limit access to tobacco products by minors. This study was unable to sample enough communities actually enforcing their tobacco age laws to draw any conclusions on the optimal frequency of enforcement. However, other studies have demonstrated dramatic decreases in the willingness of merchants to sell tobacco products to minors when serial compliance checks are done. ${ }^{11,12,17}$

US legislation, referred to as the Synar Amendment, enacted after the completion of this study, requires states to start enforcing their laws prohibiting the sales of tobacco to minors and to supply the federal government with the results of annual random compliance checks as evidence of the success of this enforcement by $1994 . .^{22}$ States not in compliance will be at risk of losing $10 \%$ to $40 \%$ of their federal grant funds for substance abuse.

At the time of our initial survey, no city sampled was conducting quarterly compliance checks using 16- to 17-year-old youths as would appear most effective based on the Woodridge and Leominster research. ${ }^{11,12} \mathrm{Re}-$ search with alcohol sales to minors in the US shows that communities doing compliance checks of all vendors have a clear pattern of lower buy rates. ${ }^{18}$ All seven communities doing compliance checks of all alcohol merchants several times a year reported purchase rates of under $20 \%$, averaging $14 \%$. Based on this and the tobacco enforcement experience, tobacco purchase rates by a 16-year-old of under $30 \%$ for tobacco should be easily accomplished and a rate of under $20 \%$ is a reasonable long-term goal. This $20 \%$ long-term goal has recently been proposed by the US Department of Health and Human Services for states to meet under the Synar Amendment. ${ }^{23}$

The cost of quarterly tobacco compliance checks is estimated by us at $\$ 35$ per establishment per year, a cost which is easily covered by the $\$ 50-\$ 70$ annual licensing fee assessed by most communities with tobacco ordinances (or by a $\$ 300$ fee recommended for most retailers by the Department of Health and Human Services ${ }^{21}$ ). The cost of compliance checks is based on our own experience assisting city inspectors in Mattoon and Schaumburg, Illinois, as well as the experience of Woodridge, Illinois. Initially six to seven establishments have been able to be surveyed per hour. This number of establishments per hour increases somewhat in later enforcement efforts as fewer establishments sell to minors and less time is taken writing out citations and talking to store managers. The cost for the youth (with fringe benefits) is calculated at $\$ 7.50$ per hour and the adult at $\$ 15$ per hour, allotting half of the inspector's time for hearings and office work and half for compliance checks with the youth. A number of small added costs and supervision costs account for the rest. Other factors such as two adult inspectors instead of one, use of police inspectors, criminal trials, longer store visits, a smaller percentage of time visiting stores, etc, may considerably increase this cost figure.

This project was financially supported by a grant from $\mathrm{Dr}$ Thomas and Dianne Radecki.

1 US Centers for Disease Control and Prevention. Cigarette smoking - attributable mortality and years of potential life lost - United States, 1990.MMWR 1993;42:645-9.

2 Pan American Health Organization (PAHO). Mortality Database. Washington, DC: PAHO, Health Situation Database. Washington, DC: PAHO,
and Trend Assessment Program, 1990.

3 Altman DG, Forster V, Rasenick-Douss L, Tye JB. Reducing the illegal sale of cigarettes to minors. $\mathscr{f} A M A$ $1989 ; 261: 80-3$.

4 DiFranza JR, Norwood BD, Garner DW, Tye JB. Legislative efforts to protect children from tobacco. fAMA 1987; 257: 3387-9.

5 Reducing minors' access to tobacco. Tobacco Youth Rep Autumn 1990; 4: 17.

6 Tobacco sales to minors in Tokyo. Tobacco Access Law News April 1993; 19: 4.

7 England, Norway, \& Finland fail to enforce tobacco laws. Tobacco Access Law News August 1992; 12:3.

8 Hoppock KC, Houston TP. Availability of tobacco products to minors. $\mathcal{f}$ Fam Pract $1990 ; 30: 174-6$.

9 US Centers for Disease Control. Differences in the age of US Centers for Disease Control. Differences in the age of
smoking initiation between Blacks and Whites - United States. $M M W R$ 1991; 40: 754-7.

10 Taioli E, Wynder EL. Effect of the age at which smoking begins on frequency of smoking in adulthood. $N$ Engl $\mathcal{f}$ Med 1991; 325: 969.

11 Jason LA, Ji PY, Anes MD, Birkhead SH. Active enforcement of cigarette control laws in the prevention of cigarette sales to minors. $\mathcal{F} A M A 1991 ; 266: 3159-61$.

12 DiFranza JR. Reducing youth access to tobacco. Tobacco Control 1992; 1:58.

13 Hines WM. Impact of a local ordinance banning tobacco sales to minors. Public Health Rep 1992; 107: 355-8.

14 State v. Emerson, 98 So.2d 225 (La. 1957).

15 STAT campaign cuts illegal sales of tobacco to minors in half. Tobacco Youth Rep Autumn 1988; 3 ,

16 More being done to prevent cigarette sales to minors. Tobacco Youth Rep Autumn 1989;4:6. 
17 Feighery EF, Altman DG, Shaffer MA. The effects of combining education and enforcement to reduce tobacco sales to minors. fAMA 1991; 266: 3168-71.

18 Radecki TE. Sales of alcohol to underage youth in 52 US cities. Drug Free Youth News 1992; 2 (suppl): 1-8.

19 Radecki TE, Strohl J. Survey of underage youth alcohol purchase habits in 17 Midwest and Eastern states. Drug Free Youth News 1991; 1 (suppl): 1-8.

20 Preusser DF, Williams AF Sales of alcol to underage purchasers in three New York counties and Washington, DC. Insurance Institute for Highway Safety: Arlington, VA. Insurand
21 Model Sale of Tobacco Products to Minors Control Act: A model law recommended for adoption by states or localities to prevent the sale of tobacco products to minors. Washington, DC: US Department of Health and Human Services; 24 May 1990.

22 Community Mental Health and Substance Abuse Services Improvement Act of 1992. Report 102-464, US House of Representatives.

23 Department of Health and Human Services. Substance abuse prevention and treatment block grants: Sale of distribution of tobacco products to individuals under 18 years of age; Proposed rules. Federal Register 1993; 58 (164): 45156-73.

\section{The daytime-only nicotine patch}

Why daytime-only? Because the profile of exposure to nicotine during the waking hours helps overcome withdrawal symptoms during the day without the need for nicotine intake at night.


icorette Patch mean plasma nicotine concentration. Ne Cune Adapted trom Olgzon and Johanatan 1200

And with abstinence rates in a doubleblind study maintained at $3-4$ times that of placebo for 2 years following cessation? that's a rationale hard to dispute.

For patlents who want to quit smoking. Nicorette Patch otiers a daytime-only simple course of treatment lasting $s$ months.

Moreover, weekly packs are tuvailable Yowing easily manageable patient costs. Fore information on the 16 -hour Nicorette 7. CaII FREEFONE 0500390114 .

WARNING: This daytime-only patch could seriously help your patients stop smoking NICOTINE-FREE DAYS START WITH PATCH-FREE NIGHTS
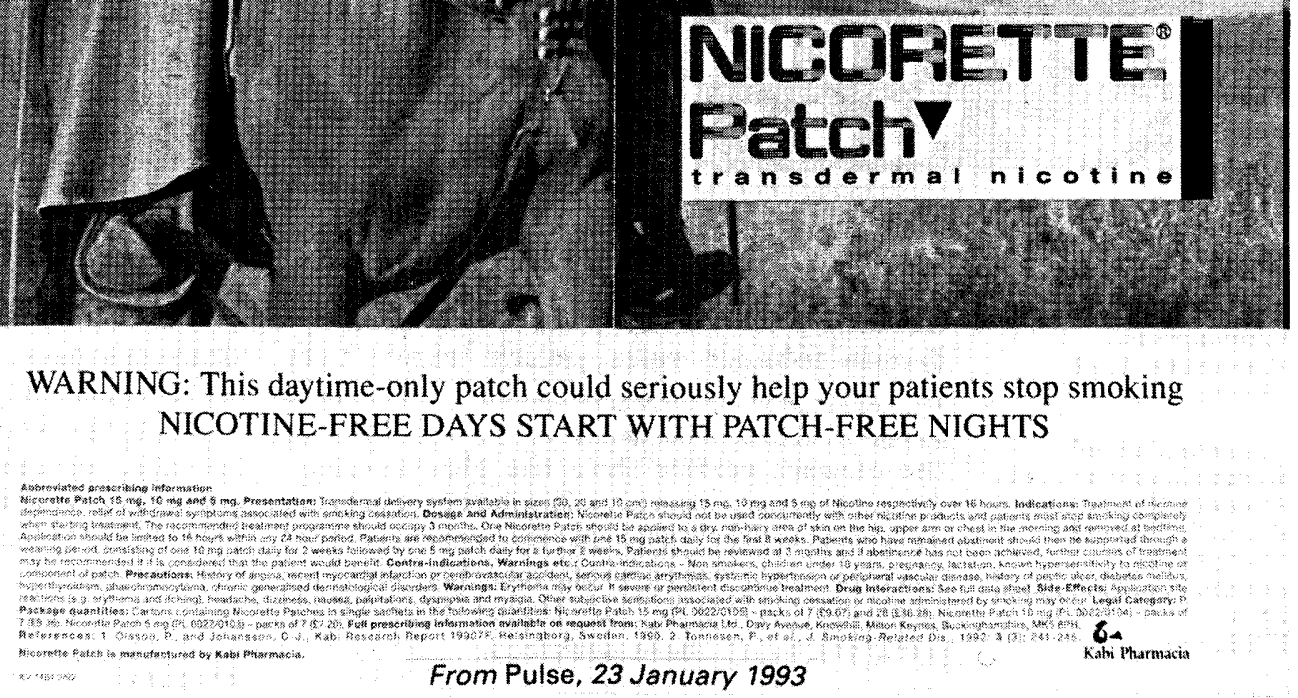

Kabi Pharmacia uses the Marlboro icon in the British medical press to promote its nicotine skin patch. Whereas many tobacco control advocates would view this ad as tame, its parody of a cigarette ad is unusual given the pharmaceutical industry's reluctance to confront the tobacco industry (see p. 334). - ED 